\title{
A PRODUÇÃO ANTECIPADA DA PROVA PARA A BUSCA DE BENS NO PATRIMÔNIO DO DEVEDOR: RUMO A UMA EXECUÇÃO MAIS EFETIVA E RACIONAL ${ }^{1}$
}

\section{JUDICIAL ANTICIPATORY TAKING OF EVIDENCE IN SEARCH OF ASSETS: TOWARDS A MORE EFFECTIVE AND RATIONAL ENFORCEMENT}

Flávia Pereira Hill Doutora e mestre em Direito Processual pela UERJ. Professora Adjunta de Direito Processual Civil da UERJ. Pesquisadora visitante da Università degli Studi di Torino, Itália. Tabeliã. Rio de Janeiro/RJ. ORCID: 0000-0001-5431-9154. E-mail: flaviapereirahill@gmail.com

RESUMO: O presente artigo almeja analisar o cabimento da ação de produção antecipada da prova com vistas a promover a busca de bens no patrimônio do devedor e, dessa forma, permitir que, municiado de tais dados, possa o credor melhor avaliar a conduta a ser adotada: (a) elaborar proposta de acordo considerando as reais possibilidades financeiras do devedor; (b) desistir da instauração da execução, por se mostrar, a priori, infrutífera; ou (c) instaurar a execução de forma consciente e responsável. O estudo pretende trazer uma contribuição de lege lata em prol do incremento da efetividade da execução no Brasil, evitando a deturpada instauração de execuções judiciais com o principal e (de fato) preparatório propósito de perquirir se o devedor possui bens em seu patrimônio. $\mathrm{O}$ manejo da ação de produção antecipada da prova, em seu novel perfil traçado no CPC/2015, disponibiliza ao operador do Direito um relevante instrumento processual de lege lata, enquanto se discute $\mathrm{e}$ providencia a previsão, no Brasil, de um modelo nacional de procedimento extrajudicial préexecutivo (PEPEX) adotado, com sucesso, em Portugal.

PALAVRAS-CHAVE: Produção antecipada da prova; Execução; Efetividade; Eficiência; Busca de bens.

\footnotetext{
${ }^{1}$ Artigo recebido em 03/03/2021 e aprovado em 14/04/2021.
} 
ABSTRACT: The present article aims to analyze the adequacy of que judicial anticipatory taking of evidence, in order to search for assets in debtor's patrimony. This proposition allows the creditor to consciously decide which action should be taken therefore: (a) make a proposal of agreement according to the real debtor's patrimony; (b) give up the fruitless intention to propose the judicial enforcement of the debt; or (c) propose, conscious and responsibly, the judicial enforcement of the debt. This study aims to present a contribution de lege lata to improve the effectiveness of judicial enforcement in Brazil, avoiding the mistaken proposal of judicial enforcement with the main and (actually) preparatory aim of finding out whether there are assets in the debtor's patrimony. The proposition of the judicial anticipatory taking of evidence in search of assets, according to its regulation brought by the Brazilian Civil Procedure Code of 2015, provides an important instrument de lege lata to reach this goal, while the creation of a pre-enforcement extrajudicial process (PEPEX) is discussed in Brazil, following the successful Portuguese experience.

KEYWORDS: Judicial anticipatory taking of evidence; Enforcement; Effectiveness; Efficiency; Search of assets.

"Um observador que só vê as coisas de fora, não vê nada.

(Marcel Proust, Em busca do tempo perdido)

\section{O drama da ineficiência da execução no Brasil: da digressão à ação.}

O Conselho Nacional de Justiça nos revela, ano a ano, uma radiografia desoladora da execução em nosso país. A execução, seja fundada em título executivo judicial (fase de cumprimento de sentença) ou extrajudicial (ação autônoma), se afigura substancialmente mais morosa do que a fase de conhecimento e ostenta taxas significativamente mais elevadas de congestionamento.

Com efeito, a duração da execução alcança a média de 7 anos e 8 meses na Justiça Federal e 6 anos e 9 meses na Justiça Estadual ${ }^{2}$. O índice de produtividade na Justiça

\footnotetext{
${ }^{2}$ CONSELHO NACIONAL DE JUSTIÇA. Relatório Justiça em Números 2020. P. 178.
} 
Estadual corresponde a 1.445 na fase de conhecimento e a apenas 774 na fase de execução, sendo que, na Justiça Federal, a disparidade se aprofunda, visto que corresponde a 1.902 na fase de conhecimento e a apenas 556 na fase de execução ${ }^{3}$.

A taxa de congestionamento da execução, na Justiça Estadual, monta a 82\%, e, na Justiça Federal, a $88 \%{ }^{4}$.

Os números, portanto, não deixam dúvidas de que, não obstante tenha havido mudanças na execução ainda no CPC/1973, com as reformas nos anos de 2005 e 2006, além daquelas oriundas da edição do CPC de 2015, infelizmente ainda estamos longe de alcançar o elevado objetivo de oferecer ao jurisdicionado brasileiro, mais especificamente ao exequente, uma execução efetiva - sem descurar, por óbvio, das garantias fundamentais do processo $^{5}$.

Em boa hora, ganha espaço o salutar e democrático debate em torno de uma possível desjudicialização da execução civil em nosso país, a partir do exame do Projeto de Lei ${ }^{\circ}$ 6.204/2019, que propõe a criação, entre nós, da figura do agente de execução - delegatários de serventias extrajudiciais com atribuição de protesto de títulos, segundo o projeto -, a quem caberia levar a efeito os principais atos executivos atualmente confiados integral e exclusivamente ao Poder Judiciário ${ }^{6}$.

No entanto, problemas complexos exigem soluções plurais, em várias frentes. E a execução civil pode, sem dúvidas, ser catalogada como um problema complexo, com raízes jurídicas e metajurídicas ${ }^{7}$, além de antigo. Trata-se de um verdadeiro "nó aselha", fácil de atar - o contingente crescente de execuções diuturnamente instauradas assim nos revela -, mas que, tensionado há anos, mostra-se de dificílimo desate.

\footnotetext{
${ }^{3}$ Idem, ibidem. P. 164.

${ }^{4}$ Idem, ibidem. P. 170.

${ }^{5}$ No tocante à importância da compatibilização entre as garantias fundamentais do processo e o fenômeno da desjudicialização, vide. HILL, Flávia Pereira. "Desjudicialização e acesso à justiça além dos tribunais: pela concepção de um devido processo legal extrajudicial". Revista Eletrônica de Direito Processual. Ano 15. Volume 22. Número 1. Janeiro a Abril de 2021. pp. 379-408.

${ }^{6}$ A respeito do Projeto de Lei ${ }^{\circ}$ 6.204/2019, vide. HILL, Flávia Pereira. Lições do isolamento: reflexões sobre Direito Processual em tempos de pandemia. Rio de Janeiro: edição do autor. 2020. Capítulo 5. pp. 75-109.

${ }^{7}$ Flavio Luiz Yarshell e Viviane Siqueira Rodrigues reconhecem que os problemas que afligem a execução transcendem as questões estritamente jurídico-processuais. YARSHELL, Flávio Luiz. RODRIGUES, Viviane Siqueira. "Desjudicialização da execução civil: uma solução útil e factível entre nós?". MEDEIROS NETO, Elias Marques de. RIBEIRO, Flávia Pereira (Coord). Reflexões sobre a Desjudicialização da execução civil. Juruá. 2020. pp. 361-372.
} 
Portanto, um olhar atento sobre a execução, em suas diferentes facetas, revela ser recomendável a adoção de diversas medidas paralelamente, cada qual voltada a contornar uma especificidade do problema.

Se, de um lado, a desjudicialização da execução acena com perspectivas reais de maior dinamicidade na execução sem comprometer o devido processo legal, por outro lado, consideramos haver uma importante dobra desse nó que merece urgente desenlace: a busca de bens ${ }^{8}$.

Frederico Marques ${ }^{9}$, com suporte em Liebman, reconhece que a execução depende não apenas de pressuposto legal (título executivo), mas também de pressuposto prático (inadimplemento). A dicotomia legal-prático é, antes de mais nada, ilustrativa da complexidade da execução, que não se esgota ou ultima nos estreitos confins do ambiente jurídico, mas, dada a sua vocação ínsita à alteração da realidade sensível, deve atuar concretamente, na prática, com vistas a satisfazer a obrigação reconhecida no título executivo. Daí por que entendemos que, ao lado do inadimplemento do devedor, um pressuposto prático não da admissibilidade da execução, mas propriamente de sua viabilidade consiste na existência de bens no patrimônio do devedor.

Araken de Assis $^{10}$ reconhece, com propriedade, que a exigência do preenchimento de legitimidade das partes e interesse de agir ${ }^{11}$ se aplica às execuções. Dessa forma, a prévia busca de bens no patrimônio do devedor consiste em providência fulcral para verificar o interesse-utilidade na instauração da execução forçada. Afinal, ainda que o exequente detenha um título executivo e esteja diante do inadimplemento do devedor, o fato de não localizar bens sobre os quais os atos executivos possam incidir esvazia, no todo ou em boa parte, a utilidade da execução, seja ela judicial ou extrajudicial.

Tanto assim que Araken de Assis reconhece que a inexistência de bens penhoráveis avulta como principal motivo para que se recaia em uma "execução infrutífera", marcada

\footnotetext{
${ }^{8}$ Leonardo Greco reconhece a busca de bens como um severo problema da execução a ser contornado. GRECO, Leonardo. "Execução civil: entraves e propostas". Revista Eletrônica de Direito Processual. Volume 12. 2013. pp. 399-445.

${ }^{9}$ MARQUES, José Frederico. Instituições de Direito Processual Civil. Volume V. Campinas: Millenium. 2000.P. 14

${ }^{10}$ ASSIS, Araken de. Manual da Execução. 18. Ed. São Paulo: Revista dos Tribunais. p. 763.

${ }^{11}$ Entendemos subsistir a categoria condições da ação no CPC/2015, a despeito de o legislador não ter feito alusão expressa a esse nomen juris. No entanto, não nos deteremos nessa questão, pois transbordaria o objetivo do presente trabalho.
} 
pela "inutilidade da tutela". Essa contingência pode ensejar a extinção anômala da execução forçada $^{12}$, que deve ser evitada, inclusive em decorrência do princípio do desfecho único ou do resultado, que deve nortear a execução.

Merece registro, nesse contexto, a recente tendência de o próprio Poder Judiciário sinalizar com a exigência da efetiva configuração de interesse de agir por parte do autor, especialmente nas ações que versem sobre direito consumerista ${ }^{13}$, mediante a indicação de que a parte autora tenha contactado o réu previamente com vistas a buscar solucionar o litígio administrativamente (seja de que forma for). Não nos caberia esgotar o tema nesta sede, mas entendemos que esse ponto ilustra um recente movimento mais amplo, voltado a promover a utilização racional e responsável da máquina judiciária, sem que isso malfira a garantia de acesso à justiça.

Se a movimentação racional e responsável da máquina judiciária é desejável na fase de conhecimento, com mais razão devemos recomendá-la no que tange à fase de cumprimento e à execução autônoma, que padecem de taxas de produtividade dramaticamente menores.

Diversos estudiosos da execução fazem coro ao proclamar que um de seus problemas sensíveis consiste precisamente na busca de bens do devedor.

Elias Marques de Medeiros Neto chama a atenção para o tema com propriedade:

"Garantir ao credor mecanismos para que ele possa, antes do início da fase de execução, obter informações quanto ao patrimônio do devedor, é, sem dúvida, uma inestimável contribuição para um processo mais efetivo, seja pelo ângulo de facilitar a atividade das partes e do magistrado quanto às futuras constrições do patrimônio do devedor, seja para se evitar processos completamente não efetivos em virtude da ausência de bens para assegurar o pagamento devido ao credor". ${ }^{14}$

No mesmo sentido, alertam Flavio Yarshell e Viviane Rodrigues:

\footnotetext{
12 ASSIS, Araken de. Manual da Execução. Op. Cit. P. 767.

${ }^{13}$ GAJARDONI, Fernando da Fonseca. "Levando o dever de estimular a autocomposição a sério: uma proposta de releitura do princípio do acesso à justiça à luz do CPC/15”. Revista Eletrônica de Direito Processual. Ano 14. Volume 21. Número 2. Maio a Agosto de 2020. pp. 99-114.

${ }^{14}$ MEDEIROS NETO, Elias Marques de. "Reflexões sobre a necessária busca antecipada de bens do devedor". MEDEIROS NETO, Elias Marques. RIBEIRO, Flávia Pereira (Coords). Reflexões sobre a Desjudicialização da execução civil. Curitiba: Juruá. 2020. P. 182.
} 
“(...) antes da desjudicialização do processo, a possibilidade de o credor conhecer previamente as condições patrimoniais do devedor pode ser uma solução para evitar processos tendentes ao fracasso, o que se faria em nome da eficiência e da busca pela efetividade da execução". ${ }^{15}$

A fim de atingir tal escopo, embora entendamos que a questão mereça uma solução de lege ferenda, com a inserção, no Código de Processo Civil, de um procedimento préexecutivo extrajudicial talhado especificamente para a busca de bens ${ }^{16}$ - tarefa sobre a qual estamos nos debruçando -, devemos reconhecer que o nosso ordenamento jurídicoprocessual nos brinda com uma adequada e útil solução de lege lata, um instrumento apto a viabilizar, desde já, a busca de bens no patrimônio do devedor: a ação de produção antecipada da prova.

Leonardo Greco pontua, com precisão, que a solução dos severos problemas que acometem a execução depende de uma atitude proativa e criativa do operador do Direito, nos seguintes termos:

"O desafio que a execução apresenta ao jurista é o de forçá-lo a abandonar uma atitude meramente contemplativa e conformista de sistematização exegética do ordenamento existente, em busca de novos paradigmas que sirvam de fundamentos para construção de um novo sistema normativo" 17 .

Firme nesse propósito, o presente trabalho objetiva examinar o cabimento da ação de produção antecipada da prova, em sua nova feição trazida pelo $\mathrm{CPC} / 2015$, com vistas a permitir que o credor possa legitimamente verificar a existência de bens no patrimônio do devedor antes da instauração da execução forçada, justamente com o propósito de lastrear a sua ponderada decisão acerca da utilidade de propô-la naquele momento ou, ainda, para embasar proposta de acordo a ser endereçada ao devedor, em consonância com a norma fundamental insculpida no artigo $3^{\circ}, \S \S 2^{\circ}$ e $3^{\circ}$, do CPC/2015.

\footnotetext{
${ }^{15}$ YARSHELL, Flávio Luiz. RODRIGUES, Viviane Siqueira. "Desjudicialização da execução civil: uma solução útil e factível entre nós?”. Op. Cit. P. 367.

${ }^{16}$ A respeito do procedimento extrajudicial pré-executivo português e a viabilidade de sua adoção no Brasil, vide. HILL, Flávia Pereira. "O procedimento extrajudicial pré-executivo (Pepex): reflexões sobre o modelo português, em busca da efetividade da execução no Brasil". In MEDEIROS NETO, Elias Marques de. RIBEIRO, Flávia Pereira (Coords). Reflexões sobre a Desjudicialização da Execução Civil. Curitiba: Juruá. 2020. pp. 305-322.

${ }^{17}$ GRECO, Leonardo. "Execução civil: entraves e propostas". Op. Cit. p. 403.
} 


\section{A nova feição da produção antecipada da prova no CPC/2015 e a sua consequente} aptidão para promover a busca de bens em preparação à (eventual) execução forçada. A tríplice finalidade da produção antecipada da prova em sua feição moderna: aclaradora, autocompositiva e preventiva.

O CPC/2015 promoveu alterações substanciais nas feições da produção antecipada da prova. No que tange diretamente à temática do presente artigo, importa salientar que o legislador, no artigo 381 do referido diploma, ampliou o cabimento da produção antecipada da prova para que passe a abarcar não apenas as tradicionais situações de urgência, nas quais o momento de produção precise ser adiantado com vistas a evitar que se torne impossível ou muito difícil a verificação de certos fatos no momento tido como regulamentar, como também em novas relevantes hipóteses, que almejam atender, além da natural finalidade aclaradora, a duas outras elevadas finalidades, a saber:

(a) finalidade autocompositiva: para que a prova produzida possa permitir a autocomposição ou outro método adequado de resolução do conflito; e

(b) finalidade preventiva: para que o conhecimento dos fatos possa justificar ou evitar o ajuizamento da ação.

A produção de provas previamente ao (eventual) ajuizamento da ação principal atende, primariamente, à finalidade aclaradora, ou seja, ao escopo de esclarecer quanto a questões fáticas juridicamente relevantes, que, inclusive, influirão na construção da estratégia das partes para lidar com o conflito em análise. Essa premissa se coaduna com a noção do direito à prova como direito autônomo e fundamental ${ }^{18}{ }^{19}$, que transcende, portanto, o direito de provar em juízo, ideia atrelada à tradicional noção de que o juiz seria

\footnotetext{
${ }^{18}$ SICA, Heitor Vitor Mendonça. O uso estratégico da Produção Antecipada de Prova no CPC de 2015. P. 02. Disponível em: https://emporiododireito.com.br/leitura/abdpro-109-o-uso-estrategico-da-producaoantecipada-de-prova-no-cpc-de-2015 Consulta realizada em 02/02/2021.

19 REICHELT, Luis Alberto. "O direito fundamental à prova e os desafios relativos à sua concretização no novo Código de Processo Civil Brasileiro”. Revista de Processo. Vol. 267. Maio 2017. pp. 197-210.
} 
o único ou principal destinatário da prova, visto que a sua produção se justificaria com o escopo único ou primordial de influir no convencimento judicial ${ }^{20}{ }^{21}$.

Ao lado da finalidade aclaradora, o CPC/2015 reconhece, em boa hora, outras finalidades igualmente relevantes. A finalidade autocompositiva se harmoniza à perfeição com a norma fundamental prevista no artigo $3^{\circ}, \S \S 2^{\circ}$ e $3^{\circ}$ do $\mathrm{CPC} / 2015$, de privilégio dos métodos de solução consensual dos conflitos em detrimento dos métodos heterocompositivos, nesta última categoria incluindo-se a adjudicação estatal. Elevar a norma fundamental o prestígio da justiça coexistencial sem municiar os operadores do Direito de instrumentos que viabilizem a sua concretização seria jogar palavras ao vento, razão pela qual a opção do legislador de ampliar o âmbito de cabimento da produção antecipada da prova com o calculado e claro escopo de prestigiar e estimular a autocomposição se mostra, a nosso sentir, coerente e acertado.

Exigir que a parte autora instaure, desde já, uma ação judicial (principal), instando o réu a se defender, quando, na verdade, o propósito maior do autor seria aguardar a fase instrutória para que, ciente de seus resultados, possa iniciar tratativas abalizadas de acordo, seria impor às partes um ônus desproporcional e contraproducente, retirando com uma mão o que o legislador havia dado, no artigo $3^{\circ}$, com a outra. Ademais, tal postura destoaria do ideal de eficiência, igualmente erigido pelo legislador ao status de norma fundamental, no artigo $8^{\circ}$ do diploma processual.

Acerta novamente o legislador ao chancelar a finalidade preventiva, reconhecendo o cabimento da produção antecipada da prova para que as partes, conhecedoras dos fatos relevantes, possam fazer a livre, consciente e responsável opção entre ajuizar ou não a ação principal. Essa hipótese de cabimento da produção antecipada da prova se coaduna perfeitamente com a visão responsável e comprometida com o bom funcionamento da máquina judiciária. Trata-se de disponibilizar ao jurisdicionado meios de adotar postura

\footnotetext{
20 "Por todas as razões postas, o juiz é o destinatário principal da prova, sobretudo, no curso do processo. Mas ele não é absolutamente o único a quem a prova interessa. A prova também tem fundamental relevância paras as partes. Em primeiro lugar, existe inequivocamente uma garantia constitucional da prova - até mesmo como expressão do acesso à justiça, ampla defesa e contraditório." WAMBIER, Luiz Rodrigues. TALAMINI, Eduardo. Curso Avançado de Processo Civil. Volume 2. 16. Ed. São Paulo: Revista dos Tribunais. 2016. P. 231.

21 RANGEL, Marco Aurélio Scampini Siqueira. MENEZES, Pedro Henrique da Silva. "Da produção antecipada de provas no projeto do novo CPC". Revista Eletrônica de Direito Processual. Vol 12. Ano 7. Julho a Dezembro de 2013. P. 569.
} 
colaborativa pré-processual, ou seja, antes e especificamente quanto ao ajuizamento ou não da ação (principal), visto que sustentamos que a cooperação deva nortear a conduta dos sujeitos do processo não apenas durante, como também antes da instauração do processo ${ }^{22}$.

Luiz Rodrigues Wambier e Eduardo Talamini pontuam, com precisão, que "a consideração do resultado probatório é muito importante para as partes dimensionarem suas efetivas razões, suas chances concretas na disputa", destacando que a importância da prova exsurge antes mesmo do início do processo, de modo a, inclusive, evitar a sua instauração ${ }^{23}$.

Marco Aurélio Rangel e Pedro Henrique Menezes igualmente reconhecem, com propriedade, que, no CPC/2015, "a prova se presta também à formação do convencimento das partes quanto às suas chances em uma eventual demanda - note, eventual demanda" 24 . E prosseguem os autores no mesmo sentido ora propugnado, pontuando ser necessário "que lhes sejam disponibilizados meios para conhecerem suas verdadeiras chances e avaliar a validade dos fundamentos que pretendem expor" ${ }^{25}$.

Assim como a leitura do CPC/2015 e da legislação processual deve ser feita de forma sistemática, a "leitura" do funcionamento do sistema de justiça deve ser feita em seu todo, pelas lentes de uma postura leal, responsável e colaborativa, especialmente em um momento histórico de colapsante sobrecarga do Poder Judiciário.

Bem vistas as coisas, acena o legislador, inclusive nos incisos II e III do artigo 381, em prol da urgência sim, mas no sentido de prestigiar a celeridade e a racionalização da atividade judiciária - e, como corolário, a eficiência -, disponibilizando, desde já, às partes instrumentos processuais consentâneos e proporcionais às suas reais pretensões naquele dado momento. Impor às partes o fardo de se envolver nos complexos meandros da ação principal quando, na verdade, elas se satisfariam com o esclarecimento dos fatos, nos

\footnotetext{
${ }^{22}$ A doutrina aponta decisão proferida em 2016 pelo TJSP que denota resistência à aplicação dos novos contornos da produção antecipada de prova consoante ora propugnamos, o que esperamos seja paulatinamente suplantado. MEDEIROS NETO, Elias Marques de Medeiros. SOUZA, André Pagani de. CASTRO, André Penteado de. MOLLICA, Rogério. "Produção antecipada de prova: primeiras manifestações dos tribunais". Migalhas. Disponível em: https://www.migalhas.com.br/coluna/cpc-na-pratica/262632/producao-antecipadada-prova--primeiras-manifestacoes-dos-tribunais Consulta realizada em 02/02/2021.

${ }^{23}$ WAMBIER, Luiz Rodrigues. TALAMINI, Eduardo. Curso Avançado de Processo Civil. Volume 2. Op. Cit. P. 231.

${ }^{24}$ RANGEL, Marco Aurélio Scampini Siqueira. MENEZES, Pedro Henrique da Silva. "Da produção antecipada de provas no projeto do novo CPC". Op. cit. P. 569.

${ }^{25}$ Idem, ibidem.
} 
remonta a idas eras. A própria noção de tutela diferenciada ${ }^{26}$, cujo conceito vem sendo corretamente decantado e dilargado paulatinamente com a evolução da ciência processual, agregado ao princípio da adequação ${ }^{27}$, consentâneo com a noção mais ampla de desjudicialização e de Justiça Multiportas, referenda a opção legislativa revelada no artigo 381.

E toda essa construção, que se consolidou nos últimos anos a respeito das novas feições da produção antecipada da prova, trazidas pelo $\mathrm{CPC} / 2015$, harmoniza-se perfeitamente, a nosso sentir, com o propósito de disponibilizar ao credor um instrumento processual voltado especificamente a permitir a busca de bens no patrimônio do devedor, de modo a, à vista da constatação acerca da saúde financeira do obrigado, consciente e responsavelmente possa o credor avaliar ser mais vantajoso elaborar uma proposta de acordo que condiga com as reais condições financeiras do devedor e lhe permita, assim, sem se submeter às agruras de uma execução, obter, ainda que parcial ou parceladamente, o crédito a que faz jus (princípio da disponibilidade ${ }^{28}$ ).

Para bem aplicar o disposto no artigo 381 do CPC/2015 faz-se necessário, por certo, interpretá-lo à luz das especificidades da hipótese ora em estudo, até mesmo porque há consenso em torno da constatação de que se afigura inviável ao legislador antever todas as possíveis circunstâncias concretas a que norma possa vir a incidir.

Sendo assim, se a ação principal consiste em uma execução de obrigação de pagar quantia certa, então, emerge, inexoravelmente, como fato juridicamente relevante ${ }^{29}$ a existência de bens no patrimônio do devedor. Como mencionado ao início do presente trabalho, sobressai a importância do aspecto prático da execução, o que corrobora o cabimento da produção antecipada da prova com a finalidade de perquirir a existência de

\footnotetext{
${ }^{26}$ PISANI, Andrea Proto. "Tutela giurisdizionale differenziata e nuovo processo del lavoro". Il Foro Italiano. Vol. 96. n. 9. Setembro. 1973. pp. 205-250.

${ }^{27}$ ALMEIDA, Diogo Rezende de. "Novamente o princípio da adequação e os métodos de solução de conflitos". ZANETI JUNIOR, Hermes. CABRAL, Trícia Navarro Xavier (Coord). Justiça Multiportas. 2. Ed. Salvador: Jus Podivm. 2018. pp. 925-952.

28 "Fundando-se o processo executivo na ideia de satisfação plena do credor, parece lógico acudir-lhe, a seu exclusivo critério, plena disposição da pretensão a executar. Diversamente do que sucede no processo de conhecimento, em que o réu possui interesse análogo na composição da lide e na extirpação da incerteza, excluindo ou não a razoabilidade da posição assumida no processo, a execução almeja o benefício exclusivo do credor. (...) Em nome dos 'princípios que informam a execução,', outorgou a lei 'amplo poder de disposição' ao credor sobre o processo". ASSIS, Araken de. Manual da Execução. Op. Cit. P. 147.

29 "'ffato relevante] é todo fato que sirva, direta ou indiretamente, para embasar as alegações das partes (o pedido do autor, a defesa do réu)". WAMBIER, Luiz Rodrigues. TALAMINI, Eduardo. Curso Avançado de Processo Civil. Volume 2. Op. cit. P. 241.
} 
bens no patrimônio do devedor, sendo certo que o resultado dessa apuração, se positivo ou negativo, será decisivo para que o credor defina se e como considera mais adequado efetivar o seu crédito.

Jordi Ferrer-Beltrán destaca a importância de se propiciar a formação do conjunto de provas "o mais rico possível”, sendo que, "para isso, dever-se-á desenhar o processo judicial de modo que esse facilite a incorporação ao processo do número máximo de provas relevantes" ${ }^{\prime 30}$. Essa concepção facilitadora da produção de provas no ordenamento jurídicoprocessual chancela a construção que ora propugnamos, voltada ao cabimento da produção antecipada da prova como forma de propiciar a aferição da existência de bens no patrimônio do devedor, com as funções aclaradora, autocompositiva e preventiva de (eventual) futura execução forçada.

Sobressai, assim, a função preventiva da produção antecipada de prova, visto que o resultado obtido balizará a decisão do credor entre propor um acordo compatível com as forças financeiras do devedor, deixar de levar a efeito a execução forçada neste momento, em razão da inexistência de bens, ou, inversamente, instaurá-la, agora ciente de que não se trata de uma aventura, de que não será mais uma execução para, de um lado, impor custos para si e para o próprio devedor, e, de outro, engrossar esterilmente as desoladoras estatísticas da execução, havendo, ao revés, fundamentos que justificam a instauração da execução forçada e sinalizam um desfecho potencialmente exitoso e promissor ${ }^{31}$.

Não nos parece despiciendo recordar que o parágrafo único do artigo 771 do CPC/2015 prevê expressamente que as disposições do Livro I da Parte Especial (precisamente onde está localizado o artigo 381) se aplica subsidiariamente ao processo de execução fundado em título extrajudicial, o que ratifica o cabimento da produção antecipada

\footnotetext{
${ }^{30}$ FERRER, BELTRÁN, Jordi. Valoração racional da prova. Salvador: JusPodivm. 2021. p. 101.

${ }^{31}$ Merece destaque o alerta feito por Leonardo Greco acerca da importância da prévia localização de bens no patrimônio do devedor para fins de configuração do interesse de agir na execução forçada, o que, a nosso sentir, reforça o cabimento da produção antecipada de prova com o escopo de busca de bens: "Afinal, qual é a finalidade da execução, o que o juiz faz na execução? Pratica atos coativos para satisfação do credor. Ele pode praticar atos coativos se nem o credor, nem o devedor, nem ele próprio juiz localizam os seus bens? Não pode. Vai praticar atos coativos sobre que? (...) Por que não se estabelece, como elemento componente do interesse de agir na execução pecuniária, a necessidade de indicação de bens e se dá ao credor a possibilidade préprocessual e o apoio estatal para ajudá-lo a localizar esses bens, mas não venha o credor a sobrecarregar inutilmente a justiça enquanto não encontrar os bens do devedor”. GRECO, Leonardo. Execução civil: entraves e propostas. Op. Cit. P. 414.
} 
da prova em preparação para a (eventual) execução forçada fundada tanto em título executivo judicial quanto extrajudicial.

\section{Especificidades da produção antecipada da prova para busca de bens no patrimônio do devedor}

O ajuizamento da ação de produção antecipada da prova com vistas a apurar a existência de bens no patrimônio do devedor ostenta claro caráter contencioso, cumprindo ao credor requerer a citação do devedor e, sendo o caso, de seu cônjuge.

A produção antecipada da prova permitirá que sejam desenvolvidas as fases de proposição, admissão e produção ${ }^{32}{ }_{-}{ }_{3}{ }_{-}^{34}$, não havendo que se falar em antecipação de sua avaliação (artigo 382, $\left.\S 2^{\circ}, \mathrm{CPC} / 2015\right)^{35}$, menos ainda de eventuais atos propriamente executivos, como os atos de constrição, passíveis de ser determinados em sede própria, notadamente no cumprimento de sentença ou na ação autônoma de execução, conforme o caso. Esse dado deve ser levado em consideração pelo credor ao optar entre ajuizar a ação de produção antecipada da prova ou deflagrar, desde logo, a execução forçada propriamente.

Nesse contexto, caberá ao autor instruir a petição inicial da produção antecipada da prova com o título executivo - extrajudicial ou judicial, nesta última hipótese, caso instaure esta nova ação em foro diverso do que prolatou a sentença condenatória, o que é perfeitamente cabível, diante da dicção do artigo 381, §2 , do CPC/2015 - , demonstrar a existência de obrigação de pagar quantia líquida, certa e exigível contra devedor - ao menos até o momento - solvente e apresentar demonstrativo discriminado e atualizado do crédito.

\footnotetext{
${ }^{32}$ WAMBIER, Luiz Rodrigues. TALAMINI, Eduardo. Curso Avançado de Processo Civil. Volume 2. Op. cit. P. 254.

${ }^{33}$ Em uma perspectiva mais ampla, Jordi Ferrer-Beltrán desdobra a atividade probatória em três momentos, a saber: a) a formação do conjunto de elementos de juízo sobre cuja base tomar-se-á a decisão; b) a valoração desses elementos; e c) propriamente, a tomada da decisão. A partir de tais lições, tem-se que a produção antecipada de prova para fins de busca de bens no patrimônio do devedor volta-se para o momento "a" antes delineado. FERRER-BELTRÁN, Jordi. Valoração racional da prova. Op. cit. pp. 61-62.

${ }^{34}$ MARINONI, Luiz Guilherme. ARENHART, Sérgio Cruz. Prova e convicção. 5. Ed. São Paulo: Revista dos Tribunais. 2019. pp. 124-125.

35 “'́ vedado ao magistrado pronunciar-se sobre o fato cuja antecipação da prova recai (art. $382, \S 2^{\circ}$ ), é dizer. A ele é vedado avaliar a prova, limitando-se a deferir o pedido relativo à sua proposição e a determinar sua respectiva produção”. BUENO, Cassio Scarpinella. Manual de Direito Processual Civil. Volume Único. 2. ed. São Paulo: Saraiva. 2016. P. 354.
} 
Cremos que o manejo da produção antecipada da prova antes do advento do termo ou condição e, de igual modo, antes de o credor providenciar a liquidação de sentença - que poderia, inclusive, ter sido provisória, na forma do artigo 512, do CPC/2015 - se mostra prematuro, desvanecendo o interesse de agir. Isso porque o patrimônio do devedor é uma universalidade, cuja composição naturalmente se modifica ao longo do tempo (dinamicidade), em razão dos próprios compromissos e atividades diários do devedor, sem que isso represente ou denote, ipso facto, conduta desleal ou fraudulenta de sua parte. Portanto, antecipar demasiadamente a busca de bens, para momento anterior ao perfazimento da condição ou termo ou da liquidação da sentença, consiste, a nosso sentir, em expediente prematuro e injustificável, via de regra.

Não nos convence eventual argumento no sentido de que a busca de bens seria útil até mesmo para que o credor avalie se irá promover a liquidação da sentença, ao pretexto de que não haveria razão para liquidar uma condenação caso não haja bens no patrimônio do devedor. No entanto, tendo em vista que, conforme ressaltamos linhas antes, o patrimônio do devedor é dinâmico, nada obsta a que haja um incremento (ou decréscimo, claro) patrimonial dentro de um lapso temporal que tende a ser significativo, de, ao menos, em um prognóstico otimista, alguns bons meses.

Merece registro, ainda, que a produção antecipada da prova, especialmente como no caso em análise, de evidente caráter contencioso, impõe ao devedor o ônus de constituir advogado para manifestar-se nos autos, em homenagem ao contraditório (corretamente prestigiado no artigo 382, $\S 1^{\circ}$, primeira parte, do $\left.\mathrm{CPC} / 2015\right)$. Portanto, não há que se considerar de todo inócuo ou "inofensivo" o ajuizamento da produção antecipada da prova, eis que produz impacto com a movimentação da máquina judiciária em si, além de ensejar a articulação da defesa pelo réu, o que, no atual estágio da ciência processual, não pode ser ignorado.

Entendemos que poderá o réu, nos autos da produção antecipada da prova em comento, refutar o preenchimento dos pressupostos processuais e das condições da ação (ou, nomeadamente, legitimidade e interesse de agir), arguir a incompetência (artigo 381, §2 $2^{\circ}$ ou a parcialidade do juízo e, no mérito, questionar se a busca de bens pleiteada pelo autor 
preenche o binômio relevância-pertinência autorizador da produção da prova ${ }^{36}{ }^{37}$, bem como se se adequa às hipóteses contempladas nos incisos do artigo 381 do CPC/2015. Do mesmo modo, a demonstração de que não se trata de obrigação líquida, certa e exigível igualmente obsta o deferimento da busca de bens. Ad exemplum tantum, tem-se o ajuizamento de ação de produção antecipada da prova contra quem não é devedor ou por quem não é credor ou, ainda, a comprovação nos autos, pelo devedor, de que a sua insolvência civil (ou falência, conforme o caso) já foi judicialmente reconhecida, o que redimensiona a questão e faz atrair o juízo universal.

Dúvidas não há de que a investigação do patrimônio do devedor ostenta, em certa medida, caráter invasivo, o que reforça a necessidade de que seja verificado o preenchimento de todos os requisitos legais antes de ser deferida a sua produção pelo magistrado.

Por outro lado, impende destacar que a produção antecipada da prova, uma vez deferida, acarretará tão somente a busca, pelo juízo, de bens no patrimônio do devedor-réu, mediante consulta aos cadastros de praxe, tais como SISBAJUD, registros de imóveis, cadastros de veículos automotores e valores mobiliários etc.

Transbordam o objeto da ação de produção antecipada da prova discussões em torno dos resultados da busca, tais como apuração acerca da penhorabilidade ou impenhorabilidade dos bens identificados, muito menos bloqueio ou constrição de bens e valores nesta sede. Tais questões poderão ser objeto de (eventual) execução forçada, que consiste na sede própria para tanto.

Do mesmo modo, pretender instaurar incidente de desconsideração da personalidade jurídica no bojo de produção antecipada da prova, a fim de que as buscas alcancem também o patrimônio do sócio (ou da sociedade, no caso da desconsideração inversa), a nosso sentir, se mostra inadequado, pois amplia sobremaneira o restrito objeto da referida ação, a demonstrar que caberia ao autor deflagrar propriamente a execução forçada.

Embora seja de todo recomendável, aqui como alhures, a prévia cientificação do réu, logo ao início da ação de produção antecipada de prova, em homenagem ao princípio cardeal

\footnotetext{
${ }^{36}$ NEVES, Daniel Amorim Assumpção. Manual de Direito Processual Civil. Volume Único. 8.ed. Salvador: JusPodivm. 2016. pp. 651-652.

${ }^{37}$ Luiz Guilherme Marinoni e Sérgio Cruz Arenhart, de forma semelhante, aludem a oportunidade e cabimento da prova. MARINONI, Luiz Guilherme. ARENHART, Sérgio Cruz. Prova e convicção. Op. cit. p. 125.
} 
do contraditório $^{38}$, excepcionalmente, consideramos admissível que o autor alegue e comprove circunstância extraordinária que demonstre que, in casu, a ciência do devedor poderá comprometer o resultado das buscas.

Nesse caso, ainda que o juiz, a pedido do autor, defira a busca de bens antes da cientificação do devedor, o ato de comunicação será apenas postergado para logo após a conclusão das buscas, jamais suprimido, diante do caráter contencioso da ação nessa hipótese ${ }^{39}$. Portanto, concluídas as buscas pelo magistrado, será o autor intimado acerca do resultado e o réu citado para manifestar-se nos autos.

A produção antecipada da prova também poderá ser útil e valiosa para que, uma vez apurado o patrimônio do devedor nessa sede, caso ele, logo após a cientificação, passe a, deliberadamente, reduzir o seu patrimônio, o autor disporá de elementos caracterizadores da conduta desleal de seu ex adverso, robustecendo subsequente alegação de fraude contra credores ou fraude à execução, conforme o caso.

Nem se diga que o diferimento da citação do réu comprometeria de todo o seu direito à ampla defesa. Com efeito, uma vez citado, poderá o réu tecer todas as alegações que vimos de indicar linhas antes, sendo examinadas e decididas pelo juízo, a ponto de, até mesmo, redundar na eventual extinção do processo e inviabilizar a utilização do resultado das buscas nos autos da futura execução forçada. Cumpre consignar que a prova antecipadamente produzida nesta sede deverá ser tratada como prova emprestada em relação à futura execução, devendo, por isso, preencher os requisitos legais para o seu regular aproveitamento, especialmente o contraditório $^{40}$ (artigo 372, parte final, CPC/2015).

\footnotetext{
${ }^{38}$ A importância do contraditório inclusive na execução forçada é destacada, com propriedade, na obra. SANTOS, Guilherme Luis Quaresma Batista. Contraditório e Execução. Estudo sobre a garantia processual do contraditório no cumprimento de sentença condenatória ao pagamento de quantia certa. Rio de Janeiro: Lumen Juris. 2013.

${ }^{39}$ Nesse sentido, em prestígio ao contraditório na produção antecipada de prova, posiciona-se Cassio Scarpinella Bueno: "O contraditório deve ser observado, a não ser que a medida não ostente caráter contencioso (art. $382, \S 1^{\circ}$ ). A previsão merece ser compreendida com ressalvas mais amplas porque não há como a lei excepcionar o contraditório quando for possível identificar o interessado, a não ser que haja urgência, o que até pode ocorrer (art. 381, I) mas não é o que cogite o dispositivo em exame. A existência ou não de litígio ('caráter contencioso') é, ademais, questão relativa, que pode ser alterada a depender do resultado da colheita das provas. Inclusive pela ausência de prévio contraditório na sua realização... Est orientação, que decorre do 'modelo constitucional do direito processual civil', deve ser observada ainda por quem queira ver, no $\S 1^{\circ}$ do art. 382, manifestação de 'jurisdição voluntária'. Não há como a lei querer se desviar do 'modelo constitucional', mesmo nesses casos, já que se regula a atuação do Estado-juiz". BUENO, Cassio Scarpinella. Manual de Direito Processual Civil. Op. Cit. P 354.

40 "As partes do segundo processo têm de haver participado em contraditório do processo em que se produziu a prova que se visa a aproveitar. Mais precisamente, é imprescindível que a parte contra a qual vai ser usada
} 
De outra parte, suprimir de todo a citação do devedor nos autos da produção antecipada de prova, ao argumento de que a sua ciência poderia ensejar a dilapidação do patrimônio ou a prática de outros atos fraudulentos apenas revela que caberia ao credor deflagrar, desde já, a própria execução forçada, e não a produção antecipada da prova, que se restringe - reiterese - à busca de bens.

O contraditório deve ser, portanto, prestigiado ao máximo na produção antecipada da prova tanto quanto em todo o sistema jurídico-processual, sendo excepcional o diferimento. Nesse sentido, Jordi Ferrer-Beltrán aponta quatro relevantes tipos de controles decorrentes do contraditório no direito probatório, a saber: 1) controle sobre a correta aplicação das regras epistemológicas e jurídicas sobre a admissão da prova, 2) permitir a produção da prova em contraditório; 3) permitir a produção de provas contrárias pelo ex adverso; 4) permitir a produção de provas de segunda ordem (provas sobre provas) $)^{41}$.

Uma vez concluídas as consultas aos bancos de dados pelo juiz, instadas as partes a se manifestar e dirimidas eventuais questões suscitadas nos estreitos limites do objeto da ação, tais como, ad exemplum tantum, casos de homonímia na titularidade dos bens apontados ou questões parelhas, o juiz prolatará sentença, mantendo os autos, caso (ainda) físicos, em cartório por um mês, para extração de cópias e certidões pelos interessados, após o que serão entregues ao autor.

O resultado das buscas será valioso ao credor para atender a diferentes finalidades, como mencionamos anteriormente:

a) lastrear a proposta de acordo a ser apresentada ao devedor, tendo em vista a maior ou menor higidez de seu patrimônio;

b) recomendar a deflagração ou não de execução forçada;

c) no caso de instauração da execução forçada, considerar o resultado das buscas para fins de indicação de bens à penhora, sendo certo que tais relatórios serão tidos como prova emprestada.

essa prova tenha sido parte no primeiro processo. (...) Não procede a assertiva de que seria desnecessária a participação do prejudicado no processo anterior, bastando que se lhe desse oportunidade de manifestação sobre a prova depois de seu traslado. É que o contraditório não consiste na simples garantia de defesa em face da prova já produzida. Mais do que isso, por meio dele assegura-se a possibilidade de participação efetiva em toda atividade judicial destinada à formação do convencimento do magistrado". TALAMINI, Eduardo. "Prova emprestada no processo civil e penal". Revista de Informação Legislativa. Brasília a. 35 n. 140 out./dez. 1998. Pp. 145-162.

${ }^{41}$ FERRER-BELTRÁN, Jordi. Valoração racional da prova. Op. Cit. P. 128. 
Diante do disposto no artigo $3^{\circ}, \S \S 2^{\circ}$ e $3^{\circ}$, c/c artigos 139 , inciso $\mathrm{V}$ e artigo $515, \S 2^{\circ}$, todos do CPC/2015, entendemos que cabe ao magistrado, nos próprios autos da ação de produção antecipada de prova, caso vislumbre possibilidade de acordo, instar as partes a encetar tratativas voltadas a celebrar avença que se volte à satisfação da obrigação, evitando novos desdobramentos, seja em juízo ou fora dele. Isso porque o CPC/2015, a par de prever que incumbe ao magistrado promover, a qualquer tempo, a autocomposição (artigo 139, inciso V), preceitua textualmente o cabimento da homologação de acordo até mesmo que envolva relação jurídica que não tenha sido deduzida em juízo (artigo $515, \S 2^{\circ}$ ). Sendo assim, é não apenas admissível, mas recomendável a celebração de acordo entre as partes, em sede de produção antecipada da prova, que convencione sobre a forma de satisfação da obrigação que ensejou a busca de bens, a ser homologada judicialmente. Com isso, atendese, a um só tempo, aos primados da economia processual, da eficiência e da valorização da autocomposição.

Por fim, cumpre salientar a importância de haver a criação de um banco de dados informatizado, que facilite a localização pelo magistrado - ou, no caso da criação do PEPEX e/ou da desjudicialização da execução, pelo agente de execução - dos bens no patrimônio do devedor ${ }^{42}$. Essa consiste, no nosso entender, em medida de suma relevância para agregar eficiência ao processo de efetivação das obrigações em nosso país.

\section{Conclusão}

Contra fatos não há argumentos e os números descortinados anualmente pelo Conselho Nacional de Justiça no Relatório Justiça em Números revelam, de forma irretorquível, a ineficiência da execução judicial em nosso país.

Trata-se de um problema complexo e antigo, que se assemelha a um "nó aselha", fácil de ser atado, mas de difícil desate. E as dobras desse nó não se cingem aos confins da ciência jurídica, embora todas elas tenham impacto sobre o nosso mister, que é justamente viabilizar, tanto quanto possível, o cumprimento (ainda que forçado) das obrigações legitimamente reconhecidas em títulos executivos. Tanto assim que Frederico Marques

\footnotetext{
${ }^{42}$ No mesmo sentido, defendendo a criação de um cadastro nacional em prol do incremento da efetividade da execução. GRECO, Leonardo. Execução civil: entraves e propostas. Op. Cit. P. 407.
} 
reconhece que a execução depende não apenas de seu espectro jurídico, mas igualmente de um relevante espectro prático.

De fato, ao lado do espectro jurídico atinente à existência de um título executivo que revele, com grau de segurança considerado suficiente pela lei, a existência de obrigação de pagar quantia certa a ser satisfeita pelo devedor, posiciona-se um relevante espectro prático. A execução forçada somente será justificável caso o devedor esteja inadimplente e, acrescente-se, somente terá mínimas chances de êxito, caso esteja presente um relevantíssimo aspecto prático: caso haja bens no patrimônio do devedor.

Descurar desse aspecto prático, atentando apenas para as questões estritamente jurídicas nos conduziu a uma verdadeira avalanche de execuções instauradas com o primordial escopo de, antes de mais nada, permitir que o credor apure se o devedor possui bens em seu patrimônio. Trata-se, com efeito, de pretensão essencialmente preparatória, com finalidade aclaradora, voltada à apuração de fatos juridicamente relevantes para a (futura e eventual) instauração da execução forçada.

Esse dado relevante nos conduz inexoravelmente ao encontro de uma medida que é nossa velha conhecida, mas que, em boa hora, ganhou novos contornos no CPC/2015: a produção antecipada da prova.

O árduo e sempre inacabado mister dos processualistas consiste em justamente detectar os "nós cegos" do nosso sistema de justiça e envidar um duplo esforço. De um lado, imediatamente, deitar o olhar sobre os instrumentos de que dispomos para, interpretando-os e deles extraindo todo o seu potencial, buscar desatar os nós com a maior presteza e tecnicidade possível. De outro lado, a médio prazo, sempre que necessário, e o presente caso assim nos parece, cunhar novos instrumentos que se mostrem mais adequados para lidar com os problemas identificados.

Desse modo, entendemos que a produção antecipada da prova, nos moldes cunhados nos incisos II e III do artigo 381 do CPC/2015 consiste em importante, adequado e útil instrumento voltado a permitir a busca de bens no patrimônio do devedor em preparação para a celebração de acordo ou para a definição sobre a instauração ou não de subsequente execução forçada, agora sim com o seu correto propósito de excussão.

A adoção da produção antecipada da prova com vistas a identificar a existência de bens no patrimônio do devedor, além de tecnicamente se adequar à perfeição ao espectro de 
cabimento talhado pelo legislador no diploma processual, favorece a autocomposição, privilegiada no artigo $3^{\circ}, \S \S 2^{\circ}$ e $3^{\circ}$, do $\mathrm{CPC} / 2015$, visto que municia o credor de elementos concretos acerca das forças financeiras do devedor, promove a eficiência, prestigiada no artigo $8^{\circ}$, do CPC/2015, pois evita a deturpada e desnecessária instauração de inúmeras execuções forçadas com o propósito primordial de busca de bens, além de, como consequência, chancelar o princípio da menor onerosidade possível para o devedor.

Entendemos que seria de todo salutar cunhar, em nosso ordenamento jurídico, um procedimento extrajudicial pré-executivo (PEPEX), inspirado na exitosa experiência lusitana, que fosse elaborado com o específico propósito de atender às diversas especificidades da busca de bens no patrimônio do devedor em nosso sistema de justiça. No entanto, a premência do tema exige de nós esforços em várias frentes e sem postergações.

Sendo assim, consideramos extremamente recomendável, tecnicamente adequado e benfazejo o emprego da produção antecipada da prova, quando o principal propósito do credor for, antes de mais nada, verificar se o devedor possui saúde financeira mínima a justificar a tomada de providências mais drásticas e, portanto, mais onerosas.

Os números nos mostram que vimos reiteradamente perdendo a guerra contra a ineficiência da execução forçada em nosso país. Se o legislador nos municiou de um instrumento que, com novos contornos, nos auxiliará a vencer, ao menos, uma importante batalha, apropriemo-nos dele, a bem da nossa missão última: a efetividade de um democrático sistema de justiça. Boas doses de criatividade, tecnicidade e bravura poderão nos levar mais longe do que poderíamos originalmente supor.

\section{REFERÊNCIAS}

ALMEIDA, Diogo Rezende de. "Novamente o princípio da adequação e os métodos de solução de conflitos”. ZANETI JUNIOR, Hermes. CABRAL, Trícia Navarro Xavier (Coord). Justiça Multiportas. 2. Ed. Salvador: Jus Podivm. 2018. pp. 925-952.

ASSIS, Araken de. Manual da Execução. 18. Ed. São Paulo: Revista dos Tribunais. 2016. BUENO, Cassio Scarpinella. Manual de Direito Processual Civil. Volume Único. 2. ed. São Paulo: Saraiva. 2016. 
CONSELHO NACIONAL DE JUSTIÇA. Relatório Justiça em Números 2020. Disponível em: https://www.cnj.jus.br/wp-content/uploads/2020/08/WEB-V3-Justi\%C3\%A7aem-N\%C3\%BAmeros-2020-atualizado-em-25-08-2020.pdf Consulta realizada em 02/02/2021.

FERRER-BELTRÁN, Jordi. Valoração racional da prova. Salvador: JusPodivm. 2021.

GAJARDONI, Fernando da Fonseca. "Levando o dever de estimular a autocomposição a sério: uma proposta de releitura do princípio do acesso à justiça à luz do CPC/15". Revista Eletrônica de Direito Processual. Ano 14. Volume 21. Número 2. Maio a Agosto de 2020. pp. 99-114.

GRECO, Leonardo. "Execução civil: entraves e propostas". Revista Eletrônica de Direito Processual. Volume 12. 2013. pp. 399-445.

HILL, Flávia Pereira. "Desjudicialização e acesso à justiça além dos tribunais: pela concepção de um devido processo legal extrajudicial". Revista Eletrônica de Direito Processual. Ano 15. Volume 22. Número 1. Janeiro a Abril de 2021. pp. 379-408.

HILL, Flávia Pereira. Lições do isolamento: reflexões sobre Direito Processual em tempos de pandemia. Versão digital. Rio de Janeiro: edição do autor. 2020. Disponível em: https://www.academia.edu/44334920/LIVRO_LI\%C3\%87\%C3\%95ES_DO_ISOLA MENTO_FL\%C3\%81VIA_HILL Consulta realizada em: 02/02/2021.

HILL, Flávia Pereira. “O procedimento extrajudicial pré-executivo (Pepex): reflexões sobre o modelo português, em busca da efetividade da execução no Brasil”. In MEDEIROS NETO, Elias Marques de. RIBEIRO, Flávia Pereira (Coord). Reflexões sobre a Desjudicialização da Execução Civil. Curitiba: Juruá. 2020. pp. 305-322.

MARINONI, Luiz Guilherme. ARENHART, Sérgio Cruz. Prova e convicção. 5. Ed. São Paulo: Revista dos Tribunais. 2019.

MARQUES, José Frederico. Instituições de Direito Processual Civil. Volume V. Campinas: Millenium. 2000.

MEDEIROS NETO, Elias Marques de. "Reflexões sobre a necessária busca antecipada de bens do devedor”. MEDEIROS NETO, Elias Marques de. RIBEIRO, Flávia Pereira (Coords). Reflexões sobre a Desjudicialização da execução civil. Curitiba: Juruá. 2020. P. 182. 
MEDEIROS NETO, Elias Marques de. SOUZA, André Pagani de. CASTRO, André Penteado de. MOLLICA, Rogério. "Produção antecipada de prova: primeiras manifestações dos tribunais". Migalhas. Disponível em: https://www.migalhas.com.br/coluna/cpc-na-pratica/262632/producao-antecipadada-prova--primeiras-manifestacoes-dos-tribunais Consulta realizada em 02/02/2021.

NEVES, Daniel Amorim Assumpção. Manual de Direito Processual Civil. Volume Único. 8.ed. Salvador: JusPodivm. 2016.

PISANI, Andrea Proto. "Tutela giurisdizionale differenziata e nuovo processo del lavoro”. Il Foro Italiano. Vol. 96. n. 9. Setembro. 1973. pp. 205-250.

RANGEL, Marco Aurélio Scampini Siqueira. MENEZES, Pedro Henrique da Silva. "Da produção antecipada de provas no projeto do novo CPC". Revista Eletrônica de Direito Processual. Vol. 12. Ano 7. Julho a Dezembro de 2013. pp. 562-580.

REICHELT, Luis Alberto. "O direito fundamental à prova e os desafios relativos à sua concretização no novo Código de Processo Civil Brasileiro". Revista de Processo. vol 267. Maio 2017. pp. 197-210.

SANTOS, Guilherme Luis Quaresma Batista. Contraditório e Execução. Estudo sobrea garantia processual do contraditório no cumprimento de sentença condenatória ao pagamento de quantia certa. Rio de Janeiro: Lumen Juris. 2013.

SICA, Heitor Vitor Mendonça. O uso estratégico da Produção Antecipada de Prova no CPC de 2015. P. 02. Disponível em: https://emporiododireito.com.br/leitura/abdpro-109-ouso-estrategico-da-producao-antecipada-de-prova-no-cpc-de-2015 Consulta realizada em 02/02/2021.

TALAMINI, Eduardo. "Prova emprestada no processo civil e penal". Revista de Informação Legislativa. Brasília a. 35 n. 140 out./dez. 1998. pp. 145-162.

WAMBIER, Luiz Rodrigues. TALAMINI, Eduardo. Curso Avançado de Processo Civil. Volume 2. 16. Ed. São Paulo: Revista dos Tribunais. 2016.

YARSHELL, Flávio Luiz. RODRIGUES, Viviane Siqueira. "Desjudicialização da execução civil: uma solução útil e factível entre nós?”. MEDEIROS NETO, Elias Marques de. RIBEIRO, Flávia Pereira (Coord). Reflexões sobre a Desjudicialização da execução civil. Juruá. 2020. pp. 361-372. 